\title{
Risk Factors, Complications and Immediate Outcome of Very Low Birth Weight Neonates in a level-III NICU
}

Sabina Yasmin ${ }^{1 *}$, Md Abdul Mannan ${ }^{2}$, Navila Ferdous ${ }^{3}$, Masuma Khan ${ }^{4}$, Parves Anwer ${ }^{5}$, Khandakar Razwan ${ }^{6}$ DOI: https://doi.org/10.3329/bccj.v9i2.56156

\begin{abstract}
:
Background: Last two decades have witnessed a steady improvement in the quality of perinatal care in Bangladesh. Around 4-8\% of all live births are very low birth weight (VLBW) \& low birth weight (LBW)is 10.6\%. The present study was done to determine risk factors, complications and immediate outcome in VLBW babies.

Methods: It was a prospective cohort study conducted in a level-III NICU of Ad-din Hospital over two years period (April 2019-March 2021). 356VLBW babies (birth weight $<1500 \mathrm{~g}$ ) were assessed for demographic characteristics, risk factors (both maternal \& fetal) and neonatal complications. The American Academy of Pediatrics protocol for neonatal resuscitation was followed for the management of VLBW. Screening for retinopathy of prematurity was done. Data were entered in predetermined proforma and statistical analysis was done.

Results: Out of 356 VLBW babies, 268 (75.2\%) survived. Maternal risk factors associated with birth of VLBW babies were primiparity $(46.8 \%)$, poor socio-economic status $(40.86 \%)$, multiple gestations $(36.83 \%)$, Premature rupture of membrane (PROM) (21.6\%), hypertension (20\%) and under nutrition (17\%). Significant morbidities were found Jaundice (43.31\%), Respiratoy Distress Syndrome (RDS) (28.08\%), apnoea (26.34\%), birth asphyxia (20.43\%), and sepsis $(22.5 \%)$. Mortality was higher among males (20.43\%) than females (12.9\%). None below 26 weeks of gestation and birth weight of $750 \mathrm{~g}$ survived. RDS was the main cause of death (46.15\%) followed by birth asphyxia (23\%), sepsis (19.2\%) and Intraventricular Haemorrhage (IVH) (11.5\%). Antenatal steroid improved the survival (77.4\%) and reduced the incidence of RDS, Necrotizing Enterocolitis (NEC) and IVH. Retinopathy of Prematurity (ROP) was detected in $30.9 \%$ VLBW babies.

Conclusions: Higher birth weight, gestational age, female sex and antenatal steroids improved survival amongst babies. Antenatal steroids reduced incidence of RDS, NEC and IVH when preterm delivery was inevitable. Judicial use of supplemental oxygen and blood products prevent development of ROP.
\end{abstract}

Keywords: Neonate, Low birth weight, NICU, Neonatal mortality, Risk factors, Very low birth weigh.

\section{Introduction}

Very low birth weight is the condition where the weight of the new born is less than $1500 \mathrm{~g}$ as against the normal weight at term between $2500 \mathrm{~g}$ and $4000 \mathrm{~g}$.Around $4-8 \%$ of all live births are very low birth weight (VLBW) infants. ${ }^{1}$ Around one-third of the neonatal deaths are witnessed in this group. ${ }^{2}$

WHO estimates that globally about 25 million LBW babies

1. Assistant Professor of Neonatology Department, Ad-din Women's Medical College \& Hospital,

2. Prof. \& Head of Neonatology Department, Ad-din Women's Medical College \& Hospital

3. Assistant Professor of Neonatology Department, Ad-din Women's Medical College \& Hospital

4. Assistant Professor of Paediatrics Department, Ad-din Women's Medical College \& Hospital

5. Assistant Registrar of Neonatology Department, Ad-din Women's Medical College \& Hospital

6. SMO of Neonatology. Ad-din Women's Medical College \& Hospital, Maghbazar, Dhaka-1217

*Correspondence:

Dr. Sabina Yasmin

Cell: 01715391251

E-mail: sabinayasmin.dmc@gmail.com were born at each year, consisting $17 \%$ of all live births, nearly $95 \%$ of them in developing countries. ${ }^{3}$ In Bangladesh, VLBW infants made up 7\%, low birth weight $10.6 \%$, respectively, of the births were preterm. Europe, where $6.2 \%$ of the births were preterm, had the lowest rate. ${ }^{4}$ In Bangladesh, VLBW infants made up 7\% of low-birth-weight total, but accounted for a third of infant's death. ${ }^{5}$

The outcome of VLBW babies is affected by prematurity as well as the presence of short-term morbidities such as RDS, patent ductus arteriosus (PDA), sepsis, NEC, IVH, periventricular leukomalacia (PVL), ROP, and chronic lung disease (CLD). Identification and thence, efforts to modify the factors associated with these morbidities will influence the intact survival of VLBW babies.

In the past two decades, the field of neonatology has experienced significant progress in medical care and improvement in overall patient survival. Advancement in technology, greater use of antenatal steroids and neonatal surfactant replacement therapy, better regionalization of prenatal and high-risk neonatal care, and a more comprehensive understanding of the physiology of the immature infants have all contributed to dramatic increase in survival of very preterm infants. ${ }^{7}$

Although they represent a small percentage of overall births and Neonatal Intensive Care Unit (NICU) admissions, VLBW 
infants are often the most critically ill and at the highest risk for mortality and long term morbidity of any NICU patient contributing disproportionately to overall hospital days and consuming a large percentage of NICU personnel time, effort and cost of care. ${ }^{8}$

Prematurity and low birth weight are major factors for neonatal mortality especially VLBW, hence this study has been undertaken with an aim and objectives to determine maternal risk factors, morbidity patterns and outcome of VLBW babies during their period of hospital stay inVLBW $(<1.5 \mathrm{Kg})$, so that necessary steps can be taken to reduce NMR in thisVLBW group and ultimately reach target NMR.

\section{Materials and Methods}

The present study was done to determine maternal risk factors, frequency of disease, complications, survival rate and risk factors for morbidity and mortality in VLBW during their period of hospital stay admitted to NICU of Addin Medical College \& Hospital.

This was a prospective cohort study conducted in a tertiary care centre, NICU of Ad-din Medical College \& hospital in Dhaka.After taking approval from IRB of AMCH, Study was done over two years period from April 2019 to March, 2021, total 2590 neonates were admitted, of those 389 neonates were enrolled for study, 33 neonates took discharge against medical advice. AllVLBW $(<1500 \mathrm{~g})$ neonates admitted within 72 hours of birth in the NICU duringstudy period were enrolled in the study. Babies with birth weight $<600$ grams, with major congenital anomalies incompatible with life were excluded. Cases were studied after taking informed consent from the parents.Gestational Age (GA) was obtained from maternal last menstrual period and confirmed with a 1 st trimester ultrasound. Then they were classified into preterm $(<37$ weeks of GA), term(37-42 weeks of GA), posterm $(>42$ weeks of GA). ${ }^{9-11}$ Gestational maturity was assessed by New Ballard Score. ${ }^{12}$ The birth weight was plotted on fetal infant growth chart by Fenton TR (2003) to classify the babies into small for gestational age (SGA) (birth weight $<10$ th percentile for GA) and Appropriate for Gestational Age (AGA) (birth weight between 10th - 90th percentile for GA).${ }^{13}$ Delivery details, birth weight, sex, ANC check up, doses of antenatal steroids were obtained from the delivery records. Maternal risk factors were assessed with proper history, physical examination and evaluating previous medical records. Maternal BP 140/90 mm mercury was taken as hypertension. (Division of nutrition, National Centre for Chronic Disease Prevention and Health). Neonates with Respiratory Distress Syndrome (RDS) received early and Continuous Positive Airway Pressure (CPAP) or Mechanical Ventilation as and when needed. Enteral feeding was initiated at the earliest and transitioned to full feeds depending on tolerance. Morbidities like Respiratory Distress Syndrome (RDS), birth asphyxia (HIE), sepsis, jaundice intraventricular hemorrhages (IVH), necrotizing enterocolitis (NEC), apnoea, pulmonary haemorrhage, PDA, Bronchopulmonary dysplasia (BPD) were predefined. IVH was graded using Volpe's classification. ${ }^{14}$ NEC was defined as per modified Bell's staging. ${ }^{15}$ Packed red blood cell transfusion was given when
Hct was $<35 \%$ in neonates with ventilator support, $<30 \%$ in neonates with heart failure \& required resp. support and $<21 \%$ in asymptomatic neonates. VLBW babies who were Appropriate for Gestational Age (AGA) were compared with those born Small for Gestational Age (SGA) in terms of associated maternal risk factors and morbidities. Appropriate investigations like hemoglobin, blood counts, serum electrolytes, blood glucose, serum bilirubin (total and direct), full septic work up, CSF study, urine examination, stool for occult blood test, chest $\mathrm{X}$ ray, Transcranial Ultrasound and Echocardiography were done to confirm diagnosis. ROP (retinopathy of Prematurity) screening was done. Data obtained were tabulated and necessary statistical analysis was done using SPSS 22 software. Descriptive statistics of the study population was generated by calculating percentages, mean and standard deviation.

Table 1: Characteristic features of the study.

\begin{tabular}{lcr}
\hline Characteristic & \multicolumn{2}{c}{ No (\%) } \\
\hline Gender & Male & $195(54.6)$ \\
& Female & $161(45.4)$ \\
Mean birth weight (mean \pm SD) & & \\
Birth weight & $<750$ & $6(1.6)$ \\
& $750-<1000$ & $29(8.2)$ \\
& $1000-1250$ & $88(25)$ \\
& $1251-1499$ & $233(65.5)$
\end{tabular}

Gestational age (GA-weeks) mean $\pm \mathrm{SD}$ )

$\begin{array}{cr}<28 & 29(8.2) \\ 28-32 & 182(51) \\ >32-36 & 119(33.4) \\ >36 & 26(7.3)\end{array}$

Birth Weight

according to GA

AGA

$267(75)$

\begin{tabular}{lcr} 
& SGA & $89(25)$ \\
Plurality & Single & $255(72)$ \\
& Twin & $37(10.4)$ \\
Place of birth & Triplet & $3(0.8)$ \\
& Inborn & $340(95.5)$ \\
& Outborn & $169(4.5)$ \\
\hline
\end{tabular}

Results:

This cross-sectional prospective study was done at AMCH in Dhaka in a level-III NICU over 2 years period, with $>95 \%$ inborn admissions. There were 195 males $(54.6 \%)$ and $161 \mathrm{fe}$ males (45.4\%). The mean birth weight was 1.198 with S.D of 0.211 . The mean gestational age in weeks was 31.9 with S.D of 3.095. Majority of them were in the gestational age 28-32 weeks $(n=182,51 \%)$, small for gestational age $(n=89,25 \%)$, singletons $(n=255,72 . \%)$, inborn $(n=340,95.5 \%)$ Table 1 depicts the findings from the study. 
Table 2 shows maternal major risk factors associated with incidence of VLBW babies were primiparity (46.8\%), poor socio-economic status (40.86\%), multiple gestations (38.8\%), PRO the (21.6\%), hypertension (20\%) and maternal under-nutrition (17\%) with AGA and SGA babies.

Table 3 Shows the relative risk of complications in AGA and SGA babies. Jaundice (43.31\%), apnoea (26.34\%), Hypoxic ischemic encephalopathy (HIE) (20.43\%), RDS (19.89\%),
Sepsis (18.82\%) were documented. Need for NICU admission and Mechanical ventilation was more among AGA babies compared to the SGA babies $(p<0.0001)$. The major indication of Mechanical Ventilation in VLBW babies was and RDS in $56(51.16 \%)$ cases) apnoea in $42(48.84 \%)$

Only 152 out of 356(42.7\%) VLBW babies received antenatal steroids. Table 4 shows that antenatal steroids improved survival in these babies ( $\mathrm{p}$ value 0.033 ).

Table 2: Association of Maternal Risk Factors with AGA and SGA babies

\begin{tabular}{|c|c|c|c|c|c|}
\hline & AGA & SGA & Odds ratio & $95 \%$ confidence interval $(C I)$ & $\mathbf{P}$-value \\
\hline \multicolumn{6}{|c|}{ Poor socioeconomic condition } \\
\hline Present & 90 & 30 & 1.00 & $0.58-1.72$ & 0.001 \\
\hline Absent & 177 & 59 & & & \\
\hline \multicolumn{6}{|l|}{ Maternal nutrition } \\
\hline $\mathrm{BMI}<18.5 \mathrm{~kg} / \mathrm{m} 2$ & 17 & 10 & 0.54 & $0.22-1.32$ & 0.133 \\
\hline $\mathrm{BMI}>18.5 \mathrm{~kg} / \mathrm{m} 2$ & 250 & 79 & & & \\
\hline \multicolumn{6}{|l|}{ Short stature } \\
\hline$<145 \mathrm{~cm}$ & 26 & 11 & 0.76 & $0.34-1.73$ & 0.483 \\
\hline$>145 \mathrm{~cm}$ & 241 & 78 & & & \\
\hline \multicolumn{6}{|l|}{ Maternal Anemia } \\
\hline $\mathrm{Hb}<11 \mathrm{~g} / \mathrm{dl}$ & 22 & 13 & 0.52 & $0.24-1.16$ & 0.080 \\
\hline $\mathrm{Hb}>11 \mathrm{~g} / \mathrm{dl}$ & 245 & 76 & & & \\
\hline \multicolumn{6}{|c|}{ Bad obstretric history } \\
\hline Present & 28 & 21 & 0.38 & $0.19-0.74$ & 0.002 \\
\hline Absent & 239 & 68 & & & \\
\hline \multicolumn{6}{|c|}{ Maternal Hypertension } \\
\hline Present & 41 & 30 & 0.36 & $0.20-0.64$ & 0.001 \\
\hline Absent & 226 & 59 & & & \\
\hline \multicolumn{6}{|l|}{ Chronic illness } \\
\hline Present & 21 & 12 & 0.55 & $0.24-1.24$ & 0.113 \\
\hline Absent & 246 & 77 & & & \\
\hline \multicolumn{6}{|l|}{ Antenatal care } \\
\hline$>3$ visit & 152 & 54 & 0.86 & $0.51-1.44$ & 0.535 \\
\hline$<3$ visit & 115 & 35 & & & \\
\hline \multicolumn{6}{|c|}{ Premature rupture of membrane } \\
\hline Present & 52 & 25 & 0.62 & $0.34-1.12$ & 0.087 \\
\hline Absent & 215 & 64 & & & \\
\hline \multicolumn{6}{|c|}{ Cervical incompetence } \\
\hline Present & 5 & 2 & 0.83 & $0.14-6.30$ & 0.557 \\
\hline Absent & 262 & 87 & & & \\
\hline \multicolumn{6}{|l|}{ Antepartum Hge } \\
\hline Present & 21 & 10 & 0.67 & $0.29-1.61$ & 0.329 \\
\hline Absent & 246 & 79 & & & \\
\hline \multicolumn{6}{|c|}{ Intrauterine infections } \\
\hline Present & 12 & 5 & 0.79 & $0.25-2.66$ & 0.426 \\
\hline Absent & 255 & 84 & & & \\
\hline
\end{tabular}


Table 3 : Relative risk of complications in AGA and SGA babies.

\begin{tabular}{|c|c|c|c|c|c|c|}
\hline & & AGA & SGA & $\begin{array}{c}\text { Relative } \\
\text { risk (RR) }\end{array}$ & $\begin{array}{l}95 \% \text { confidence } \\
\text { interval }(\mathrm{CI})\end{array}$ & P value \\
\hline \multirow[t]{2}{*}{ Respiratory distress syndrome(RDS) } & Yes & 82 & 18 & 1.13 & $1.01-1.28$ & 0.057 \\
\hline & No & 185 & 71 & & & \\
\hline \multirow[t]{2}{*}{ Apnoea } & Yes & 74 & 16 & 1.13 & $1.00-1.28$ & 0.067 \\
\hline & No & 193 & 73 & & & \\
\hline \multirow[t]{2}{*}{ Hypoxic Ischemic Encephalopathy } & Yes & 21 & 8 & 0.96 & $0.76-1.22$ & 0.737 \\
\hline & No & 246 & 81 & & & \\
\hline \multirow[t]{2}{*}{ Pul. Hemorrhage } & Yes & 10 & 2 & 1.12 & $0.86-1.45$ & 0.387 \\
\hline & No & 257 & 87 & & & \\
\hline \multirow[t]{2}{*}{ Polycythemia } & Yes & 42 & 12 & 1.04 & $0.89-1.22$ & 0.609 \\
\hline & No & 225 & 77 & & & \\
\hline \multirow[t]{2}{*}{ Jaundice } & Yes & 78 & 27 & 0.99 & $0.86-1.13$ & 0.840 \\
\hline & No & 189 & 62 & & & \\
\hline \multirow[t]{2}{*}{ Anemia } & Yes & 21 & 10 & 0.89 & $0.70-1.15$ & 0.329 \\
\hline & No & 246 & 79 & & & \\
\hline \multirow[t]{2}{*}{ (DIC) } & Yes & 26 & 16 & 0.81 & $0.63-1.03$ & 0.037 \\
\hline & No & 241 & 73 & & & \\
\hline \multirow[t]{2}{*}{ Sepsis } & Yes & 64 & 16 & 1.09 & $0.95-1.24$ & 0.241 \\
\hline & No & 203 & 73 & & & \\
\hline \multirow[t]{2}{*}{ Pneumonia } & Yes & 18 & 7 & 0.96 & $0.74-1.23$ & 0.719 \\
\hline & No & 249 & 82 & & & \\
\hline \multirow[t]{2}{*}{ Meningitis } & Yes & 5 & 2 & 0.95 & $0.59-1.53$ & 0.557 \\
\hline & No & 262 & 87 & & & \\
\hline \multirow[t]{2}{*}{ Hypoglycemia } & Yes & 18 & 15 & 0.71 & $0.52-0.97$ & 0.004 \\
\hline & No & 249 & 74 & & & \\
\hline \multirow[t]{2}{*}{ Hyperglycemia } & Yes & 23 & 10 & 0.92 & $0.73-1.17$ & 0.460 \\
\hline & No & 244 & 79 & & & \\
\hline \multirow[t]{2}{*}{ Acute kidney Injury (AKI) } & Yes & 3 & 0 & 1.34 & $1.26-1.42$ & 0.421 \\
\hline & No & 264 & 89 & & & \\
\hline \multirow[t]{2}{*}{ Necrotizing enterocolitis (NEC) } & Yes & 18 & 5 & 1.05 & $0.84-1.31$ & 0.709 \\
\hline & No & 249 & 84 & & & \\
\hline \multirow[t]{2}{*}{ Patent ductus arteriosus (PDA) } & Yes & 48 & 13 & 1.06 & $0.92-1.23$ & 0.465 \\
\hline & No & 219 & 76 & & & \\
\hline \multirow[t]{2}{*}{ Intraventricular hemorrhage (IVH) } & Yes & 7 & 4 & 0.84 & $0.54-1.33$ & 0.285 \\
\hline & No & 260 & 85 & & & \\
\hline \multicolumn{7}{|l|}{ Bronchopulmonary } \\
\hline \multirow[t]{2}{*}{ Dysplasia } & Yes & 4 & 1 & 1.07 & $0.69-1.66$ & 0.633 \\
\hline & No & 263 & 88 & & & \\
\hline
\end{tabular}


Bangladesh Crit Care J September 2021; 9 (2): 94-100

Table 4: Relation of outcome with antenatal steroids

\begin{tabular}{lccccc}
\hline & Incidence & \multicolumn{2}{c}{ Antenatal steroid } & Total & P value \\
\hline RDS & Yes & $40(26.32)$ & $60(29.41)$ & 100 & 0.520 \\
& No & $112(73.68)$ & $144(70.59)$ & 256 & \\
\multirow{2}{*}{ NEC } & Yes & $12(7.89)$ & $9(4.41)$ & 21 & 0.168 \\
& No & $140(92.11)$ & $195(95.59)$ & 335 & \\
\multirow{2}{*}{ IVH } & Yes & $5(3.29)$ & $6(2.94)$ & 11 & 0.542 \\
& No & $147(96.71)$ & $198(97.06)$ & 345 & \\
\hline
\end{tabular}

Table 5: Relative risk of complications in AGA and SGA babies.

\begin{tabular}{lccccc}
\hline & & \multicolumn{2}{c}{ Outcome } & Total & P value \\
\hline Antenatal & Given & $126(45.3)$ & Expired n(\%) & & 0.059 \\
steroid & Not given & $152(54.7)$ & $52(66.7)$ & 152 & 204 \\
& Total & $278(100)$ & 78 & 356 \\
\hline
\end{tabular}

\section{Discussion:}

Due to advance of prenatal and neonatal care now a day's more preterm and very low birth weight babies are survived. However, published data on outcomes of very low birth weight infants from Bangladesh are limited. Morbidities and mortality of VLBW babies vary between countries and in different hospitals as a result of specific treatment pattern employed in individual intensive care units. Incidence of VLBW neonates $(1.7 \%)$ in this report was lesser than from other countries; world-wide prevalence of VLBW babies has been reported between $5-7 \%$ and that of ELBW as $1 \%$; however, studies from the United States reported as 1.1\% and $0.7 \%$ respectively. ${ }^{16}$ This study was conducted in a level three NICU in a tertiary hospital; therefore, our figures may not represent nationwide prevalence of very low birth weight infants.

Majority (54.6\%) of VLBW babies admitted, were males which was much higher than the normal sex distribution of the general population of the country, probably indicating preference of the parents to seek health care for the male babies. Mannan et al. ${ }^{17}$ in Bangladesh showed that $62.86 \%$ of VLBW babies in their study were male, values being quite similar to this study, showing male sex as a risk factor for VLBW delivery. Maternal risk factors associated with incidence of VLBW babies in this study were primiparity, PROM, hypertension and under-nutrition. Undernutrition, hypertension, PROM and APH were found to be associated more with the incidence of SGA babies in comparison to AGA babies. Mannan et al. ${ }^{17}$, Manganaro et al. ${ }^{4,18}$, and Roy et al. ${ }^{19}$ found the similar risk factors as common associations contributing to the increased incidence of VLBW babies in varying percentages. Majority (76.4\%) of VLBW babies in this study were preterm with significant proportion $(39.62 \%)$ being both preterm and SGA, the results being quite similar to previous studies ${ }^{16,18}$ suggesting that multiple factors were acting together. Neonatal Jaundice,RDS, sepsis, apnoea, HIE, pulmonary hemorrhage, PDA and NEC were found to be significant morbidities. Compared to the study of Mannan et al., the incidence of jaundice and RDS were much higher in this study but the incidence ${ }^{17}$.

The incidence of IVH was quite similar in both studies. Ahmed et al. ${ }^{20}$ showed the incidence of Jaundice needing phototherapy to be $26.7 \%$ whereas in this study the incidence was much higher (43.31\%). Incidence of birth asphyxia was found to be much lower $(20.43 \%)$ compared to their study reflecting improved perinatal care. Anemia was detected in 31 cases $(9.68 \%)$ out of which10 $(5.38 \%)$ needed blood transfusion in the present study, the incidence being comparable with the study of Ahmed et al.

Neubauer et al. ${ }^{21}$ showed that $72 \%$ of mothers having been given antenatal corticosteroids for neonatal RDS prophylaxis, $46 \%$ of ELBW developed RDS and $41 \%$ received surfactant treatment. Raju et al. ${ }^{22}$ showed the incidence of RDS as $12 \%$ at 33-34 week, $2 \%$ at $35-36$ week and $0.11 \%$ at term in their study of outcome of late preterm infants. Overall incidence of RDS was found to be much higher $(28.08 \%)$ in this study probably due to poor coverage of antenatal steroids. However, exposure to antenatal steroids was found to be associated with improved survival and significant reduction of incidence of RDS, NEC and IVH. Higher birth weight \& gestational age and female sex were each found to be associated with improved survival which has been well established in previous studies. ${ }^{20}$

The American Academy of Pediatrics ${ }^{23}$ reported the BPD rate among infants $<1500 \mathrm{~g}$ to be $23 \%$. Lemons et al ${ }^{24}$ also showed BPD affected $23 \%$ of all infants. Zhang et al. ${ }^{25}$ reported the incidence of BPD to be $48.3 \%$ in infants with BW of $\leq 1500 \mathrm{~g}$. 
In our study, the incidence of BPD was $1.4 \%$. Appropriate respiratory support with a policy for safe administration of oxygen, optimal fluid and nutrition management and infection controls at proper time, might be associated with the low incidence of BPD.

The incidence of ROP among ELBW babies in our study (78.6\%) was slightly lower than the study of Nelumdeniya et al. ${ }^{26}(83.3 \%)$, but much higher than that of Neubauer et al. ${ }^{21}$, $(10 \%)$.

Ninety-two babies $(78 \%)$ survived during the study period. Rate of overall survival for VLBW newborns has been widely different in studies from different parts of the world, $63 \%$ from India, $35.6 \%$ from a study in Iran, $70 \%$ and $71 \%$ and from South Africa, $74.5 \%$ from Turkey. ${ }^{27-29}$ These differences mainly related to gestational age, birth weight and associated diseases of the newborns and standard care of NICU in different studies. Neonates' weighing $\leq 700$ grams at birth had the highest mortality rate. None of them survived, similar to other studies. ${ }^{29,30}$ Main cause of mortality in our patients was RDS leading to respiratory failure; perinatal asphyxia, sepsis and major congenital anomalies were also common causes of death, which need improving quality of care in the antenatal, perinatal and postnatal periods of the newborn.

Limitations: This was a hospital-based study and does not give a complete idea of the community at large. Further follow up studies are necessary to have a better understanding of the long-term outcome among the survivors.

Conclusions: Proper antenatal and perinatal care is necessary to prevent the incidence of VLBW babies and the associated complications. Higher birth weight and gestational age, female sex and exposure to antenatal steroids were associated with improved survival and reduction of morbidities. Prematurity and need for neonatal intensive care were associated with poor audiological outcome.

Recommendations: Widespread coverage with antenatal steroids should be done when preterm delivery is inevitable. Judicial use of supplemental oxygen and blood products should be done to prevent development of ROP. Regular follow up of the survivors for growth monitoring, neurodevelopmental assessment and early detection of complications with prompt intervention, to have a neurologically intact outcome with minimum disability will be highly appreciated and remain as crucial.

\section{Reference:}

1. Fanaroff AA, Stoll BJ, Wright LL, Carlo WA, Ehrenkranz RA, Stark $\mathrm{AR}$ et al. Trends in neonatal morbidity and mortality for very low birthweight infants. Am J Obstet Gynecol. 2007;196(2):147.

2. United Nations. Department of Economic. The Millennium Development Goals Report 2008. United Nations Publications. Available at http://www.un.org/en/development/desa/publications/ millennium-d evelopment-goals-report-2008.html

3. Negi KS, Kandpal SD, Kukreti M. Epidemiological factors affecting low birth weight. JK Sci. 2006; 8:31-4.
4. Manganaro R, Gemelli M, Mamì C, Mancuso A, Rizza ML, et al. (1991) [Analysis of factors associated with very low birth weight (less than or equal to $1500 \mathrm{~g}$ )]. Minerva Ginecol 43: 283-286.

5. National Neonatology Forum of India. National Neonatal Perinatal Database. Report 2002-03. New Delhi: National Neonatology Forum of India; 2002-03. p. 1-70

6. March of Dimes, PMNCH, Save the Children, WHO. Born Too Soon: The Global Action Report on Preterm Birth. Eds CP Howson, MV Kinney, JE Lawn. World Health Organization. Geneva, 2012

7. Nandini Naskar, Arakhita Swain, Kedar Nath Das and Abhaya Kumar Patnayak, Cuttack: 753007, Odisha, India Maternal Risk Factors, Complications and Outcome of Very Low Birth Weight Babies: Prospective Cohort Study from a Tertiary Care Centre in Odisha. J Neonatal Biol 2014, 3:3 DOI: 10.4172/2167-0897. 1000142

8. Eichenwald EC, and Stark AR. (2008). Management and outcomes of very low birth weight. NewEngland J Med. 2008;358(16): $1700-11$

9. DiPietro JA, Allen MC (1991) Estimation of gestational age: implications for developmental research. Child Dev 62: 1184-1199.

10. Lynch CD, Zhang J (2007) The research implications of the selection of a gestational age estimation method. Paediatr Perinat Epidemiol 21 Suppl 2: 86-96.

11. Delpachitra P, Palmer K, Onwude J, Meagher S, Rombauts L, et al. (2012) Ultrasound Reference Chart Based on IVF Dates to Estimate Gestational Age at 6-9 weeks' Gestation. ISRN ObstetGynecol 2012: 938583 .

12. Sasidharan K, Dutta S, Narang A (2009) Validity of New Ballard Score until 7th day of postnatal life in moderately preterm neonates. Arch Dis Child Fetal Neonatal Ed 94: F39-44.

13. Fenton TR (2003) A new growth chart for preterm babies: Babson and Benda's chart updated with recent data and a new format. BMC Pediatr 3: 13 .

14. Volpe JJ (1989) Intraventricular hemorrhage and brain injury in the premature infant. Neuropathology and pathogenesis. ClinPerinatol $16: 361-386$

15. Walsh MC, Kliegman RM (1986) Necrotizing enterocolitis: treatment based on staging criteria. PediatrClin North Am 33: 179-201.

16. Butler AS, Behrman RE, editors. Preterm birth: causes, consequences, and prevention. National Academies Press; 2007 May 23.

17. Mannan MA, Jahan N, Dey SK, Uddin MF, Ahmed S (2012) Maternal and foetal risk factor and complication with immediate outcome during hospital stay of very low birth weight babies. Mymensingh Med J 21:639-647

18. Manganaro R, Gemelli M, Mamì C, Mancuso A, Rizza ML, et al. (1991) [Analysis of factors associated with very low birth weight (less than or equal to $1500 \mathrm{~g}$ )]. Minerva Ginecol 43: 283-286.

19. Roy KK, Baruah J, Kumar S, Malhotra N, Deorari AK, et al. (2006) Maternal antenatal profile and immediate neonatal outcome in VLBW and ELBW babies. Indian J Pediatr 73: 669-673

20. Ahmed A, Rob MA, Rahman F, Rahmann Huda R. Preterm Very LowBirth Weight Babies: Outcome of Admitted Newborns at A CommunityLevel Medical College Hospital in Bangladesh. Journal of Bangladesh College of Physicians and Surgeons.2008 Sept; 26(3).

21. Neubauer AP, Voss W, Kattner E (2008) Outcome of extremely low birth weight survivors at school age: the influence of perinatal parameters on neurodevelopment. Eur J Pediatr 167: 87-95 
22. Raju TN, Higgins RD, Stark AR, Leveno KJ (2006) Optimizing care andoutcome for late-preterm (near-term) infants: a summary of theworkshop sponsored by the National Institute of Child Health andHuman Development. Pediatrics 118: 1207-1214

23. Committee on Fetus and Newborn (2002) Postnatal corticosteroids to treat or prevent chronic lung disease in preterm infants. Pediatrics 109(2): 330-338.

24. Lemons JA, Bauer CR, Oh W, Korones SB, Papile LA, et al. (2001) Very Low Birth Weight outcomes of the National Institute of Child Health and Human Development Neonatal Research Network, January 1995 through December 1996. Pediatrics 107(1): 1-8.

25. Zhang H, Fang J, Su H, Chen M (2011) Risk Factors for Bronchopulmonary Dysplasia of Neonates Born at $\leq 1500 \mathrm{~g}$ of Birth Weight (1999-2009) Pediatr Int 53(6): 915-920.

26. Nelumdeniya UB, De Silva PS, Nanayakkara S, Sridharan S, Srirathnakumar K, Abeysirigunawardena RC, Marasinghe SS. Short term outcome, complications and average direct cost in managing extremely low birth weight infants in a tertiary care centre in Sri Lanka. Sri Lanka Journal of Child Health .2012; 41(4).
27. Basu S, Rathore P, Bhatia BD. Predictors ofmortality in very low birth weight neonates in India.Singapore Med J. 2008 Jul;49(7):556.

28. Navaei F, Aliabady B, Moghtaderi J, Moghtaderi M,Kelishadi R. Early outcome of preterm infants withbirth weight of $1500 \mathrm{~g}$ or less and gestational age of 30 weeks or less in Isfahan city, Iran. World JPediatr. 2010 Aug 1;6(3):228-32.

29. Canbak Y, Silfeler I, Dorum BA, Kurnaz H, DorumS. The ratio of mortality and morbidity in very lowbirth weight infants in a public hospital. TurkishPediatr Arch. 2011 Jun:144-51 (26)

30. Battin MR, Knight DB, Kuschel CA, Howie RN.Improvement in mortality of very low birthweightinfants and the changing pattern of neonatalmortality: The 50 - year experience of one perinatalcentre. $J$ Paediatr Child Health. 2012;48(7):596-9. 